\title{
Discursos sobre el Eclesiastés de Salomón: ¿Una obra de Pedro de Valencia atribuida a Benito Arias Montano?
}

Avelina Carrera-de la Red

Universidad de Valladolid

ORCID ID: https://orcid.org/0000-0001-8685-1372

Los Discursos sobre el Eclesiastés de Salomón se dedican a la interpretación literal del libro bíblico, colocando la exégesis léxica y gramatical del original hebreo en el centro del comentario. Tradicionalmente atribuidos a Benito Arias Montano, este artículo propone la consideración de Pedro de Valencia como posible autor de la obra, atendiendo a dos consideraciones fundamentales: una externa, el gusto particular que sentía Valencia por los discursos o tratados redactados en castellano, frente a su escasa presencia en las obras de Montano; y otra interna, las numerosas concordancias textuales que se dan entre los Discursos y la obra de Valencia, especialmente en lo referente al que denomino «racionalismo adánico,» tema de capital importancia para el intérprete.

Palabras Clave: Exégesis bíblica; sentido literal; racionalismo adánico; problemas de autoría.

Discursos sobre el Eclesiastés de Salomón. A Pedro de Valencia's Work Attributed to Benito Arias Montano?.- The Discursos sobre el Eclesiastés de Salomón offer a literal interpretation of the biblical book, placing the lexical and grammatical exegesis of the Hebrew original at the heart of their commentary. The Discursos having traditionally been attributed to Benito Arias Montano, this article proposes considering Pedro de Valencia as the possible author of that work, on the basis of two fundamental considera-

\footnotetext{
"Este trabajo se ha realizado en el marco del Proyecto de Investigación del Plan Nacional I+D+I «Tradición clásica, y Patrística y Exégesis Bíblica en el Humanismo (Monarquía Bíblica de Lorenzo de Zamora y Epistolario de Pedro de Valencia)» (ref. núm. FFI2015-65007-C4-4-P).

***avelina@fyl.uva.es

Copyright: (C) 2018 CSIC. Este es un artículo de acceso abierto distribuido bajo los términos de la licencia de uso y distribución Creative Commons Reconocimiento 4.0 Internacional (CC BY 4.0).
} 
tions: one external, the particular liking Valencia had of discourses and treatises written in the Castilian language, as opposed to their sparse presence among Montano's works; the other internal, the numerous textual concordances between the Discursos and the work of Valencia, in particular regard to what I refer to as «Adanic rationalism,» a theme of vital importance for the interpreter.

KeYwords: Biblical exegesis; Literal sense; Adanic rationalism; Authorial attribution.

Los Discursos sobre el Eclesiastés de Salomón, declarado según la verdad del sentido literal (s.d.) son una obra exegética dedicada, como su título indica, a ofrecer la interpretación literal del libro bíblico, tratando de alcanzar su sentido último. Versículo a versículo, se van desgranando sus doce capítulos, insistiendo en la significación originaria de los términos hebreos y en la explanación de la simbología del texto.

Los tres manuscritos que se han conservado se encuentran en la Biblioteca del Monasterio de San Lorenzo de El Escorial, donde parece probable que se hicieran las copias: la primera (Ms. g.IV.32) en el siglo XVII, a cargo de Juan de la Puebla; la segunda (Ms. I.III.24), en el siglo XVIII, probablemente obra de Juan de Soto; y la tercera (Ms. Ma 22-1-9), quizá también del XVIII, relacionada textualmente con la anterior. La obra ha sido recientemente publicada por Valentín Núñez Rivera en la colección «Bibliotheca Montaniana» de la Universidad de Huelva. Se trata de una magnífica edición crítica, en la que se cotejan los tres manuscritos, y además, se editan los cuatro folios que en el primero de ellos siguen a los Discursos ${ }^{1}$.

En su estudio preliminar, el editor analiza pormenorizadamente los problemas que plantea la autoría de la traducción y del comentario del Eclesiastés ${ }^{2}$. Básicamente, los copistas apuntan hacia dos posibles autores. Sin dar razón de por qué, Juan de la Puebla en el título de su copia atribuye el texto a Benito Arias Montano: Discursos sobre el Eclesiastés de Salomón declarado según la verdad del sentido literal por el doctor Arias Montano. Por contra, el segundo manuscrito en una nota interior, igualmente sin ofrecer las motivaciones para ello, señala como autor a fray José de Sigüenza, prior de

\footnotetext{
${ }^{1}$ Benito Arias Montano (atribuido), Discursos sobre el Eclesiastés de Salomón declarado según la verdad del sentido literal, ed. Valentín NúñEz RIVERA (= Bibliotheca Montaniana 24 [Huelva: Servicio de Publicaciones Universidad de Huelva, 2012]). Tomo esta edición como texto base para mi estudio.

${ }^{2}$ Discursos sobre el Eclesiastés, págs. 11-16.
} 
los monjes Jerónimos y bibliotecario escurialense durante algunos años en el último tercio del siglo XVI. La balanza de la autoría parece inclinarse hacia Montano. Como señala Núñez, la huella de Sigüenza no se reconoce en la conformación literaria de esta obra. En cambio, existen notorios paralelismos entre algunos pasajes de los Discursos y diversos textos montanianos, en su mayor parte tomados de Naturae Historia, Humanae salutis Monumenta y De arcano sermone, además de que Montano publicó al final de los Hymni et Saecula un poema latino versionando el Eclesiastés, e hizo de la enseñanza de las Sagradas Escrituras el eje central de toda su vida. Sin embargo, como Núñez también declara, a esta adscripción se le podrían hacer dos objeciones. Para empezar, los tres manuscritos contienen referencias a Arias Montano en tercera persona. No deja de sorprender que la copia que en el título lo considera el autor, en el interior remita a una de sus obras con la nota: Vide «Elegiam de poenitentia» Benedicti Ariae Montani, Himna ${ }^{3}$. A la vista de algunas amplificaciones y supresiones que se dan entre las tres versiones, el editor plantea la posibilidad de que en un primer momento esta anotación fuese marginal, obra de algún alumno del biblista, y acabase más tarde siendo incorporada al texto. Otra posible objeción a la autoría de Montano es el hecho de que el tratado esté escrito en castellano, y no en latín. Como indica Núñez, la obra castellana del extremeño se ubica fundamentalmente en su juventud, en tanto que la fecha de composición de los Discursos, si bien no se puede determinar con exactitud, debería localizarse entre 1585 y 1592 , tiempo de la segunda y tercera estancias de Montano en El Escorial, a juzgar por el complejo proceso de copia que se comprueba en su transmisión, propio de esta etapa de la producción montaniana.

A la vista de estas consideraciones y tras la atenta lectura de los Discursos sobre el Eclesiastés, partiendo de aspectos relacionados con el contexto, la forma y el contenido de la obra, creo que podría abrirse una tercera vía en la cuestión de su autoría, proponiendo al humanista extremeño Pedro de Valencia como posible autor o, al menos, coautor de la misma ${ }^{4}$.

\footnotetext{
${ }^{3}$ Discursos sobre el Eclesiastés, pág. 234. En los otros dos manuscritos también hay referencias similares: Vide Ariam Mont. pulcherrime tractat illum locum, Vide Ariam Mont. sup. hunc locum, Vide doctorem in Corpore Operis Magni, in Natura y Vide Montanum in Corpore Operis Magni (cit. en Discursos sobre el Eclesiastés, pág. 13).

${ }^{4}$ No sería esta la primera obra que pendiese al mismo tiempo de la mano de Montano y de Valencia. «Hemos de mencionar el caso del Tractatus de perfectione christiana, cuya atribución a Arias Montano o a Pedro de Valencia no ha sido totalmente delimitada»,
} 


\section{Pedro de Valencia, principal amanuense y colaborador de Arias Montano}

Las figuras de Benito Arias Montano y Pedro de Valencia están muy unidas a nivel humano y doctrinal. El discípulo admira a su maestro; desde el espíritu crítico que este mismo le inculca como principio básico en la búsqueda de la verdad, asimila su doctrina y se impone como obligación personal transmitirla y darla a conocer. Así lo proclama abiertamente:

Y juntamente haré muestra de cuán provechosa sea la lección de los libros que dejó impresos y escritos Arias Montano, mi señor y aficionadísimo servidor de V.S., porque todo lo demás que aquí referiré de la Escritura será traído y aplicado conforme a sus interpretaciones y consideraciones, y la misma muestra me atrevería a hacer con cualquiera otra materia filosofal o teológica, natural, moral o política ${ }^{5}$.

Se dice que el hecho de ser fray José de Sigüenza amanuense circunstancial de Arias Montano pudo llevar a atribuirle a él los Discursos, quizá identificando la letra del original con la letra de otras copias de obras montanianas. Lo cierto es que durante la mayor parte de su vida, el primer amanuense de Montano fue Pedro de Valencia. Sus cartas están llenas de referencias a esta ocupación, tan prolongada en el tiempo que en ocasiones le provoca la inquietud de no poder dedicarse a su propia producción, como hace saber a su admirado Padre Sigüenza:

Prosigue Arias Montano en el Cuerpo de su obra y en el Comentario de Isaías y a mí me ocupa mucho en el copiar, de manera que no me dexa tiempo para otras cosas en que parar. Yo me podría ocupar con vtilidad de otros, y el copiar quienquiera podría, pero él lo ordena así, y está bien: Ut particeps fiam, etc. ${ }^{6}$

señala Jesús M. ${ }^{a}$ NiETo IbÁÑEz en la Introducción a Obras completas. Volumen IX: Escritos espirituales.1. San Macario (Valladolid: Consejería de Educación y Cultura León: Universidad de León, 2001) pág. 45.

${ }^{5}$ Discurso sobre materias del Consejo de Estado, Madrid, BN MSS/11160, fol. 29r. En la transcripción de los textos de este Manuscrito modernizo la puntuación y la grafía.

${ }^{6}$ Carta de Pedro de Valencia a Fr. José de Sigüenza (Zafra, 15 de noviembre de 1593), en Pedro de Valencia, Epistolario, eds. Fco. Javier Fuente Fernández y Juan Fco. Domínguez Domínguez (Madrid: Ediciones Clásicas, 2012) pág. 82. 
Incluso a la muerte de Montano, Valencia asume de inmediato la tarea de copiar, corregir y tratar de publicar los manuscritos que aquél había dejado inéditos ${ }^{7}$. Pero no se trata de una mera labor de transcripción. Con este ejercicio, Valencia asimila, aprende y enjuicia la doctrina de Montano, especialmente en el campo de la exégesis bíblica. El propio biblista se alegra de los logros que ha conseguido en la formación de su discípulo y amigo, a quien se dirige con el afecto de un padre ${ }^{8}$. A menudo, Pedro de Valencia actúa también como correa de transmisión de esta doctrina, difundiéndola y debatiéndola, especialmente con miembros del círculo bíblico de El Escorial y del círculo humanista del sur de la Península. En este sentido, es determinante su amistad, rayana en devoción, con fray José de Sigüenza'. Así lo deja ver en muchas de las epístolas que le dirige. Sirva de muestra este fragmento:

Parescionos conueniente que acabase el Commentario de Isaías, aunque cessase entre tanto la prosecucion del Cuerpo. Los últimos papeles que me embió de Isaías son hasta fin del cap. LVII y yo entiendo deue llegar, sigún el paso lleua, más adelante del sesenta. Es este comentario otro Opus Magnum, y confío ha de ser bien recibido. Cierto que yo, aunque conozco tanto a A. Montano y espero siempre dél grandes cosas, pero que cada vez que veo nueuos papeles suyos vençen toda mi expectación y me pareze que no es possible ser suyos. Quisiera poder referir aquí todo lo

\footnotetext{
${ }^{7}$ Vid. Carta de Pedro de Valencia a Juan Moreto (Zafra, 18 de octubre de 1598), en Pedro de Valencia, Epistolario, eds. Fco. Javier Fuente Fernández y Juan Fco. Domínguez Domínguez (Madrid: Ediciones Clásicas, 2012) págs. 323-327.

${ }^{8}$ Vid. Dedicatoria de Arias Montano a Pedro de Valencia del Salmo 31, en Pedro de Valencia, Epistolario, eds. Fco. Javier Fuente Fernández y Juan Fco. Domínguez Domínguez (Madrid: Ediciones Clásicas, 2012) pág. 311.

${ }^{9}$ Según Gaspar Morocho, la amistad entre Pedro de Valencia y el Padre Sigüenza debió de fraguarse durante la última estancia de Arias Montano en la Biblioteca de El Escorial, entre enero y abril de 1592; vid. «Introducción a una lectura de Pedro de Valencia. Primera parte (1555-1587)», en Pedro de Valencia. Obras completas. Volumen I: Introducción general, fuentes y estudios, coords. Jesús M. ${ }^{a}$ NiETo IBÁÑEZ, Raúl LóPEZ López, Antonio Reguera Feo y Manuel A. Seoane Rodríguez (León: Universidad de León, 2015) págs. 113-62 (Primera versión en Obras completas. Volumen V, Relaciones de Indias. 1, Nueva Granada y Virreinato de Perú, coord. Gaspar Morocho Gayo [León: Universidad de León, 1993] págs. 15-60). Precisamente en la Biblioteca de El Escorial se conserva buena parte de la correspondencia cruzada entre Valencia y Sigüenza, Ms. L.I.18, fols. $7 \mathrm{a}-40 \mathrm{~b}$.
} 
que he copiado estos días dende el cap. XL, que comienza Consolamini, porque sé cierto serían de grande consolación para V.P. ${ }^{10}$

No sabemos si Montano conoció la traducción castellana que hizo Valencia de su Dictatum Christianum, publicado en las prensas de Plantino en 1575. Probablemente el zafrense se aplicó a la versión, que tituló Lección cristiana, después de la muerte de su maestro, quien, sin duda, le habría dado su total aprobación.

Por todo ello, no son de extrañar las numerosas coincidencias de base que se dan entre Arias Montano y Pedro de Valencia.

\section{La verdad del sentido literal. Referencia a Pedro de Valencia EN EL MANUSCRITO DEL SIGLO XVII}

El primer y más importante nexo de unión entre el autor de los Discursos sobre el Eclesiastés, Arias Montano y Pedro de Valencia es su voluntad declarada de situar las fuentes originales de los textos sagrados en el centro de la interpretación bíblica.

En la copia de fray Juan de la Puebla, el nombre de Pedro de Valencia aparece inmediatamente después de los Discursos, al referirse a él un autor desconocido que realiza algunas «observaciones sobre la edición de los Libros Santos que trataba de imprimir el padre fr. Andrés de León» ${ }^{11}$. En ellas se hace referencia a la controversia mantenida entre Pedro de Valencia y Juan Ramírez, por una parte, y el Padre Andrés de León, por otra, a propósito de las objeciones y enmiendas planteadas por este último a la versión latina de la Paráfrasis Caldaica contenida en la Biblia Regia. El autor de las observaciones del Manuscrito de El Escorial toma partido por los defensores de la versión montaniana, alegando que se sustentan en el conocimiento de los libros sagrados y antiguos, y de las lenguas originales en las que se escribieron, así como en la unión entre razón y religión católica que se desprende de sus argumentos:

\footnotetext{
${ }^{10}$ Carta de Pedro de Valencia a Fr. José de Sigüenza (Zafra, 5 de septiembre de 1594), en Pedro de Valencia, Epistolario, eds. Fco. Javier Fuente Fernández y Juan Fco. Domínguez Domínguez (Madrid: Ediciones Clásicas, 2012) pág. 87.

${ }^{11}$ Real Biblioteca del Monasterio de El Escorial, Ms. g.IV.32, fols. 83v-85v; vid. Discursos sobre el Eclesiastés, págs. 11-12, donde Núñez Rivera edita estas anotaciones y apunta su posible atribución al Padre Sigüenza.
} 
La diferencia que hay entre el padre Andrés de León, de una parte, acerca de la impresión de la Biblia que el dicho padre trata de hacer, y Pedro de Valencia y el Licenciado Juan Moreno Ramírez, su hermano, que la contradicen, es muy fácil de entender, y de juzgar, no solamente de los teólogos y letrados, que saben qué cosa son libros antiguos y sagrados, y lenguas en que fueron escritos de principio y traducciones de ellos en otras más conocidas y vulgares; sino que también la pueden entender y juzgar cualesquier hombres de razón y entendimiento que tienen la noticia que deben de la cristiana y la católica religión que profesan ${ }^{12}$.

Los argumentos a favor de conservar la Paráfrasis tal como la imprimió Montano se recogen en un extenso memorial titulado: Advertencias de Pedro de Valencia y Juan Ramírez acerca de la impresión de la Paráfrasis Caldaica ${ }^{13}$. Los autores comienzan su alegato declarando la dificultad de la tarea, que consiste básicamente en justificar un buen número de términos latinos de la versión de la Biblia Regia que pretendía modificar el Padre León:

Con facilidad y brevedad se quita de una versión un vocablo y se sustituye otro sin dar razón de la causa, porque se sabe. Pero mostrar que ni el vocablo que estaba primero se debiera quitar ni ponerse el que se sustituyó, y que la versión antes de trocarla es la cierta y no después de alterada, ni es fácil ni breve. Lo primero ha hecho el padre Andrés de León. Lo segundo hemos procurado hacer nosotros, y así no han podido dejar de alargarse estas Advertencias ${ }^{14}$.

Los más de un centenar de lugares bíblicos sometidos a juicio crítico se explican a través de aclaraciones gramaticales, semánticas y contextuales que dejan ver un profundo conocimiento de las lenguas originarias de la Biblia. Los autores tienen como objetivo fundamental del trabajo ofrecer la correspondencia de cada término latino con su original hebreo y caldeo, y, en algún caso, siríaco o arábico.

Cuando se trata de estudiar los textos sagrados, fuente viva de la verdad revelada, el criterio de Arias Montano y Pedro de Valencia coincide

\footnotetext{
${ }^{12}$ Discursos sobre el Eclesiastés, pág. 11.

${ }^{13}$ Advertencias de Pedro de Valencia y Juan Ramírez acerca de la impresión de la Paráfrasis Caldaica, eds. Avelina Carrera de la Red y Antonio Reguera, en Pedro de Valencia, Obras completas. Volumen II: Escritos bíblicos y teológicos, coord. Jesús M. ${ }^{a}$ NiETo IBáÑEz (León: Universidad de León, 2014) págs. 557-654.

${ }^{14}$ Advertencias de Pedro de Valencia y Juan Ramírez, pág. 566.
} 
plenamente, teniendo siempre como punto de partida el temor de Dios y la interpretación literal de su palabra. Así se desprende de una carta que escribió Valencia en 1604 al Padre Sigüenza en defensa de su maestro, cuyo método exegético estaba siendo severamente atacado por entender sus críticos que prestaba más atención a la letra que al espíritu:

Los que desearen que todos los versos i palabras se interpreten a la letra de Christo haránlo con zelo de Dios, sed non secundum scientiam, porque con esta generalidad infirman la fuerça de los verdaderos testimonios ${ }^{15}$.

En el título completo de la obra cuya autoría se trata de dilucidar, Discursos sobre el Eclesiastés de Salomón, declarado según la verdad del sentido literal, se deja ver cómo la intención primera del autor es ajustarse en su exégesis a la letra del texto para llegar a descifrar la verdad que transmite. La esencia del comentario consiste en el análisis de los términos hebreos originales, su forma gramatical, significado y simbología. Además de esto, como señala Núñez Rivera ${ }^{16}$, el comentarista se aplica a desentrañar la estructura retórica del escrito y sus mecanismos compositivos, mostrando en todo momento un interés eminentemente didáctico, muy en consonancia con el objetivo central de un discurso, a juicio de Pedro de Valencia:

Los tratados y discursos en cada arte y ciencia se enderezan principalmente a enseñar a los que no saben, y a convencer y desengañar a los que contradicen y están persuadidos de contrarias opiniones ${ }^{17}$.

3. El discurso en castellano, género habitual en la obra de Pedro de VAlencia

Se dice que el hecho de que los Discursos estén escritos en castellano supone una cierta dificultad para la atribución de esta obra a Arias Montano, pues en su madurez, tiempo en el que se suponen redactados, este autor utiliza en su escritura preferentemente la lengua latina. Por

\footnotetext{
${ }^{15}$ Carta de Pedro de Valencia a Fr. José de Sigüenza (Zafra, 27 de mayo de 1604), en Pedro de Valencia, Epistolario, eds. Fco. Javier Fuente Fernández y Juan Fco. DomíngueZ Domínguez (Madrid: Ediciones Clásicas, 2012) págs. 174-175.

${ }^{16}$ Discursos sobre el Eclesiastés, pág. 20.

${ }^{17}$ Discurso sobre materias del Consejo de Estado, fol. $27 \mathrm{v}$.
} 
el contrario, excepción hecha de los Academica (la única obra que publicó en vida) y algunos opúsculos, la inmensa mayoría de los trabajos de Valencia están escritos en castellano. No se trata de desconocimiento del latín, pues en todo momento da sobradas muestras de su saber lingüístico y filológico, tanto en las lenguas clásicas como en las bíblicas. Parece, más bien, que siente la necesidad de expander su pensamiento a cualquier ámbito y persona. Los discursos proliferan particularmente entre sus escritos sociales y económicos: Discurso sobre materias del Consejo de Estado, Discurso en materia de guerra y estado compuesto de sentencias y palabras de Demóstenes, Discurso contra la ociosidad, Discurso para que en la reducción de los gastos no se suprima parte de las limosnas, Discurso sobre la expulsión de los moriscos, y así hasta más de una docena de títulos. También su obra exegética está eminentemente en castellano: De la tristeza según Dios y según el mundo, De los autores de los libros sagrados, Para declaración de una gran parte de la estoria apostólica en los «Actos» y en la «Epístola ad Galatas,» etc. Parece que una persona tan comprometida con su sociedad y con la búsqueda de la verdad encuentra en esta forma literaria y en su propia lengua un vehículo apto para la exposición y difusión de sus ideas.

\section{Los DisCURSOS SOBRE EL ECLESIASTÉS Y EL «RACIONALISMO ADÁNICO» de Pedro de Valencia}

Junto a la intensa complicidad literaria y personal que se da entre Arias Montano y Pedro de Valencia, la predilección que éste siente por determinados temas lo identifican de forma particular. La nota dominante de buena parte de su obra es el planteamiento binario sobre el que se articula: Existen dos tipos de filosofía, la sagrada, revelada por Dios a través de su palabra, y la humana, que enseña el arte de vivir. En consecuencia, hay dos tipos de sabiduría, la divina, contenida en las Sagradas Escrituras, y la que el hombre aprende a través de la ciencia y las disciplinas académicas. Asimismo, hay dos tipos de razón, la razón impresa por Dios en el corazón del hombre a través de la ley natural, y la razón humana, cuyo principal afán ha de ser conectar con la anterior. El hombre tiene dos tipos de alma: la superior, masculina, iluminada por la luz de Dios a través de la razón, y la inferior, femenina, comunicada directamente con los sentidos corporales. Todas estas dicotomías se derivan del pecado original. Si en el Paraíso reinaba la 
armonía entre Dios y sus criaturas, la caída de Adán, seducido por la mujer, a su vez engañada por la serpiente, condenó a sus hijos a una vida marcada por las tribulaciones y la esforzada búsqueda de la verdad, con la muerte en el horizonte como inexorable e inquietante final.

Las correspondencias entre los Discursos sobre el Eclesiastés y esta línea argumental son manifiestas; el autor sustenta puntos centrales de su interpretación sobre ideas muy similares a las de Pedro de Valencia ${ }^{18}$. A fin de acotar la confrontación del comentario con la extensa obra del humanista extremeño, me fijo especialmente en su Discurso sobre materias del Consejo de Estado, breve tratado compuesto a instancias de uno de los miembros de este organismo, cuya principal función consistía en asesorar directamente al monarca en cuestiones relativas a la vida política y civil ${ }^{19}$.

El Eclesiastés nace precisamente en un palacio; el libro es obra de un rey, «Rey de Jerusalén» dice de sí mismo (1.1). Desde esta condición se dirige a su pueblo para instruirlo: «Y más que fue apañante sabio y aun enseñó sabiduría al pueblo y le hizo escuchar, e investigó y enderezó parábolas mucho» ${ }^{20}$.

La explicación del término «apañante» se da en el arranque de la obra con la interpretación del sintagma Verba cohelet, «palabras del apañador ${ }^{21}$. El autor del libro se aplica a sí mismo este nombre. El intérprete explica que se trata de una palabra tomada del hebreo,

en género femenino y quiere decir apañante, o allegante, la que apaña, la que recoge, o allega: y ansí en la fuerza hebrea, porque la mente, o lo

\footnotetext{
${ }^{18}$ Las resonancias textuales alcanzan, incluso, a un poema castellano copiado en el primer manuscrito escurialense, inmediatamente después de las mencionadas observaciones sobre la Paráfrasis caldaica. Los versos relatan cómo la caída del hombre en el Paraíso representa el punto en el que se alejó de su Creador, frente al estado de conexión directa que en un principio existía entre la razón divina y la razón humana; el único objetivo genuino de nuestra vida debe ser buscar la unión con Dios a través de la verdadera sabiduría; vid. Discursos sobre el Eclesiastés, págs. 54-58.

${ }^{19}$ Pedro de Valencia se ofrece a desarrollar su tratado como una obra más extensa si su destinatario lo requiere: «Solamente con brevedad pondré en suma la compostura de todo el tratado que contenga todo el discurso y los fundamentos de él [...] y no por esto me quiero escusar de escribir el tratado entero si entendiere que tiene gusto de ello V.S.» (Discurso Consejo de Estado, fol. 29r).

${ }^{20}$ Discursos sobre el Eclesiastés, pág. 281; traducción de Ec 12:9-10.

${ }^{21}$ Discursos sobre el Eclesiastés, págs. 83-84.
} 
que los poetas llaman la musa, dentro de sí dijo estas palabras después de muy pensadas; y son no sólo palabras, sino verdad y realidad de historia ${ }^{22}$.

Hay que diferenciar el término hebreo dābāar, «que significa no sólo palabras, sino la consideración, el pensamiento y la historia y realidad de las cosas», del término 'āmar «palabras, voces o hablar», subrayando que no se trata de un discurso vacío, sino bien pensado ${ }^{23}$. El Eclesiastés es obra de un hombre sabio:

No entendáis, dice, que esta doctrina tan grave y tan paradoja para los hombres de este siglo nació de algún caprichoso o antojadizo, etc., sino que es de hombre verdaderamente sabio y que la ha sacado a luz todo lo que ha podido su ingenio rastrear, recoger y allegar con la sabiduría y experiencia $^{24}$.

En él se aúnan el conocimiento humano y el revelado por Dios:

No hay más de dos maneras de saber, la una por las causas y principios naturales conocidos por razón y ingenio, o por experiencia larga, la otra por revelación y por las Sagradas Escrituras y principios sobrenaturales ${ }^{25}$.

Siempre habla desde el corazón:

Su corazón, que en la Sagrada Escritura significa el principio y la raíz de todas las obras del hombre, vio y experimentó mucho de sabiduría y de ciencia ${ }^{26}$.

Verba cohelet, por lo tanto, significa los pensamientos que reunió y meditó un hombre lleno de sabiduría, rey y rector de su asamblea, dándolos a conocer como testimonio verdadero para la edificación de su pueblo.

Desde la perspectiva de Pedro de Valencia, las palabras del cohelet podrían serle de gran utilidad a un hombre de Estado como aquel que le había pedido consejo. Pero su obra trasciende a un único destinatario y pretende ayudar a instruir a sus lectores en la auténtica filosofía de vida, el «arte de vivir humana que les convendrá seguir a los hombres para su

\footnotetext{
${ }^{22}$ Discursos sobre el Eclesiastés, pág. 84.

${ }^{23}$ Discursos sobre el Eclesiastés, pág. 84.

${ }^{24}$ Discursos sobre el Eclesiastés, pág. 281.

${ }^{25}$ Discursos sobre el Eclesiastés, pág. 165.

${ }^{26}$ Discursos sobre el Eclesiastés, pág. 114.
} 
conservación y bien en particular y en público ${ }^{27}$. Aprender a discernir la verdadera sabiduría significa trabajar en el seguimiento de los mandatos de la voluntad divina desde el interior de uno mismo:

La que se deleita con la ley de Dios y se rinde a ella es la sabiduría del espíritu, cuyo consejo y guía tienen obligación de seguir todos los hombres y repúblicas del mundo por ley divina y natural, so pena de $\operatorname{errar}^{28}$.

El paso de las tinieblas a la luz solamente puede hacerse mirando la vida con el corazón:

Como dice el Señor a San Pablo: Mitto te aperire oculos eorum, id convertantur a tenebris ad lucem et de potestate Satanas ad Deum. Y el mismo Apóstol dice que rogaba a Dios que abriese a los fieles estos ojos del espíritu que él llama ojos del corazón ${ }^{29}$.

Hay, pues, en ambos textos una marcada intencionalidad didáctica y doctrinal. En este sentido, el intérprete del Eclesiastés y Pedro de Valencia inician su exposición defendiendo como principal «modo de enseñar» el «metódico», que consiste en asentar los principios y fundamentos de un arte o una ciencia como introducción al estudio de una materia. Dice el comentarista:

Cuatro modos de enseñar hay en los antiguos muy usados [...] El último modo de saber es metódico, reduciendo cada cosa a sus géneros, como los filósofos, unos a diez, y otros a tres, y otros a quince géneros y de allí, en sabiendo la cosa de que han de tratar, luego miran a qué género se reduce y de allí componen y resuelven hasta que vienen a tener entera noticia [...] Del cuarto usa aquí Salomón, como sapientísimo, y quiere mostrar una proposición admirable y reducilla a sus principios, y ponella en género para que sin engaño y con mucho orden se sepa ${ }^{30}$.

El Discurso de Valencia comienza también hablando de método:

El buen modo de enseñar y dar doctrina para la firmeza y claridad de ella, es comenzándola por sus principios y fundamentos, los cuales en

\footnotetext{
${ }^{27}$ Discurso sobre materias del Consejo de Estado, fol. 30r.

${ }^{28}$ Discurso sobre materias del Consejo de Estado, fol. $64 \mathrm{v}$.

${ }^{29}$ Discurso sobre materias del Consejo de Estado, fol. 56r.

${ }^{30}$ Discursos sobre el Eclesiastés, págs. 83-84.
} 
cada arte y ciencia son propios de aquella ciencia y diferentes de las de los demás, y también en una misma arte [...] se presuponen diferentes principios, y se usan diversos términos y lenguaje. Pero es ley del método de doctrina que el que es peripatético y sigue por autor a Aristóteles, use de los términos y principios de él; y el que a Zenón, use de lenguaje y fundamentos estoicos; y el que a Platón, académico es; y así en las otras sectas y vías de filosofía, sin confundir ni mezclar los principios ni los términos, so pena de oscuridad, confusión y de no concluirse nada cierto ni firme ${ }^{31}$.

Desde el principio del Eclesiastés se fija claramente su proposición fundamental:

Y la proposición es que Todo cuanto hay en el mundo y todo cuanto a los hombres pone cuidado y fatiga en él es nada ${ }^{32}$.

Esta sentencia recoge la sustancia de toda la obra; con ella abre y cierra su libro:

Por todos los estados ha ido discurriendo Salomón en este libro: miró primero al hombre como a particular y como rey, y después como miembro de la república y político, y en todo lo halla lleno de vanidad y de locura, y de opiniones erróneas y torcidas, y a vuelta de una cosa buena mil malas ${ }^{33}$.

Por eso está también omnipresente en el intérprete, y el final del discurso es el recuerdo de que el hombre está abocado a la muerte y sólo el alma es inmortal; la consideración de esta inexorable realidad certifica la conclusión de que las cosas que llenan la vida son vanas y vacías (riquezas, títulos, afanes, incluso los estudios mundanos a los que afanosamente se aplica el sabio):

Y así al hombre no le viene nada y la parte y porción suya es sólo que se alegra y regocija y esta se acaba con la muerte y se torna la carne en polvo y el alma va a dar en las manos de Dios. Luego bien se ve que todo es nada y la suma de todas estas partidas son nada ${ }^{34}$.

Y todo desde aquella primera caída en el Paraíso:

\footnotetext{
${ }^{31}$ Discurso sobre materias del Consejo de Estado, fol. 29r-v.

${ }^{32}$ Discursos sobre el Eclesiastés, pág. 84.

${ }^{33}$ Discursos sobre el Eclesiastés, pág. 219.

${ }^{34}$ Discursos sobre el Eclesiastés, pág. 280.
} 
Tan caído está el hombre de aquel estado excelente en que Dios le había hecho singularísimo y excelente [...] Esta es la suma y el todo, nada ${ }^{35}$.

Por su parte, Pedro de Valencia también insiste en que el nada, las tinieblas y la muerte envuelven la vida de los hijos de Adán que se apartan del conocimiento de Dios:

Y así, desviándose de la sabiduría y luz de Dios, que es esencial, cayeron en el nada y tinieblas de la astucia diabólica, que no tiene consistencia, fundamento ni ser, sino que su ser (digamos así) está en el no ser, en el desvío y apartamiento de la sabiduría y del ser y de la verdad [...] Desamparando, pues, el hombre el mundo espiritual y cayendo en las tinieblas de este aire en que es la potestad del enemigo, y apartándose del Verbo Divino en que está la vida y luz de los hombres, cayó en el nada y en la muerte en que antes había caído Lucifer ${ }^{36}$.

Los hijos de Adán nacen muertos:

Dificultosa cosa es, y aun imposible, dar a entender al hombre animal esta muerte del hombre interior, porque él nace muerto, y nunca ha experimentado la vida, como al ciego de nacimiento no se le puede dar a entender qué cosa sea estar ciego, y qué cosa es la vista y la luz y los colores. Adán y su mujer muy bien se sintieron morir en cuanto a la vida del espíritu por el pecado porque pasaron de la vida a la muerte de un golpe ${ }^{37}$.

En el Eclesiastés, Dios es el 'ělōhîm, el gobernador «que gobierna y dispone todas las cosas del mundo» ${ }^{38}$. Los hombres a menudo se empeñan en ir contra su ley:

No se han contentado los hombres locos y soberbios de intentar mudar y trocar el orden natural y la sazón de las cosas, y a buscar desatinados medios para sus fines vanos y perdidos, mas aún han querido atreverse contra Dios y trabucar sus intentos y salir ellos con sus imaginaciones y que no ejecute y cumpla Dios sus designios ni llegue al cabo sus motivos ${ }^{39}$.

La verdadera sabiduría consiste en evitar tan vano intento y ajustarse al gobierno divino:

\footnotetext{
${ }^{35}$ Discursos sobre el Eclesiastés, pág. 162.

${ }^{36}$ Discurso sobre materias del Consejo de Estado, fols. 31v-32r y 51r.

${ }^{37}$ Discurso sobre materias del Consejo de Estado, fols. 49v-50r.

${ }^{38}$ Discursos sobre el Eclesiastés, pág. 157.

${ }^{39}$ Discursos sobre el Eclesiastés, pág. 157.
} 
No ha de haber atrevimiento en la criatura para querer estorbar los motivos de Dios, sino sólo temer y obedecer a sus juicios, que esto es lo que quiere y tiene ordenado y esta es la sabiduría del hombre y lo que puede hacer bien ${ }^{40}$.

La obra de Pedro de Valencia está llena de referencias a un rey y a su reino; pero no se refiere a una realeza terrena sino a Dios mismo. La conciliación de ambas monarquías se localiza en los orígenes de la creación; es Dios, señor del universo, quien «con la majestad del Creador» pone al hombre al frente del «reino de la tierra» ${ }^{41}$. Es obligación del hombre desempeñar su oficio al frente de lo creado ajustándose a los mandatos del sumo artífice. Quienes detentan el poder han de buscar en toda ocasión el bien y la justicia, tal como vienen establecidos por la ley divina, enfrentándose así a quienes

quisieran quitar todas las leyes del mundo y todos los reyes, príncipes y jueces, con toda la fuerza cohatiba de la justicia, y más quisieran quitar a Dios del cielo y del mundo y su providencia ${ }^{42}$.

Con su tratado, Pedro de Valencia busca mostrarles la senda que no han de abandonar:

El principal intento y documento de este tratado es mostrar que a ninguna criatura ni a ningún reino ni república le ha estado ni estará bien jamás quererse conservar y acrecentar por injusticia, haciendo enemigo al Todopoderoso ${ }^{43}$.

De aquí se desprende que la fuente principal de conocimiento sean las Sagradas Letras, únicas depositarias de la verdad revelada por Dios ${ }^{44}$. Se dice en los Discursos:

\footnotetext{
${ }^{40}$ Discursos sobre el Eclesiastés, pág. 158.

${ }^{41}$ Discurso sobre materias del Consejo de Estado, fols. 30v-31r.

${ }^{42}$ Discurso sobre materias del Consejo de Estado, fol. $68 \mathrm{v}$.

${ }^{43}$ Discurso sobre materias del Consejo de Estado, fol. 30r.

${ }^{44}$ En el marco del Humanismo cristiano, son muchos los autores del Renacimiento que encuentran en la Biblia la primera fuente de inspiración para la elaboración de su teoría política y social. Así, los escritos sociales de Pedro de Valencia se nutren en buena medida de las ideas políticas expuestas por Arias Montano en su Comentario al Libro de Josué y en el Comentario al Apocalipsis; vid. Gaspar Morocho GAYo, «El humanismo español en Pedro de Valencia: Tres claves para su interpretación», en Pedro de Valencia. Obras completas. Volumen I en Pedro de Valencia. Obras completas. Volumen I: Introducción
} 
Si vas a buscar lo sólido y lo firme y la verdad, no la hallarás en el que entre manos tienes y vas leyendo, y en el que te trabajas y fatigas. Y ansí es menester ver luego otro, para ver si estará allí y acontesciendo lo mismo. No hallarás descanso interno. Amonéstote, hijo, que si lo quieres, no lo busques en otro libro que en el de la Sagrada Escritura, que aquí sólo está ${ }^{45}$.

También para Pedro de Valencia el conocimiento de la ciencia sagrada ocupa la cúspide del saber:

Comenzaré distinguiendo dos suertes solas que la doctrina de Dios enseña y propone de sabiduría, la una para que la aborrezcamos y huyamos, y la otra para que la amemos, elijamos y sigamos, y los principios, autores y maestros de ellas ${ }^{46}$.

Así se entiende que ambos textos se adentren en la historia sagrada, indagando en ella las causas que pudieron acabar con el hombre en su actual estado de postración. Se trata de un recorrido a través de la historia humana; uno y otro Discursos consideran que las narraciones bíblicas son reales, no simples símbolos o alegorías, por más que puedan ir adornadas con metáforas, parábolas y figuras que ayuden a los hombres en la intelección del mensaje divino. Las palabras del Eclesiastés son tan verdad como que nacen de la propia experiencia de su autor:

La mente de este hijo de David, rey poderoso y sabio, dijo estas palabras, que son verdadera historia, colegidas y recogidas de la larga inducción y experiencia que como poderoso y sabio tuvo ${ }^{47}$.

A propósito del engaño de la serpiente a Adán y Eva, dice Pedro de Valencia:

Toda esta narración es verdadera y pasó de la manera que se cuenta [...] Y la conveniencia de aquella historia con la doctrina no la hizo ficción ni composición humana, sino divina sabiduría y traza del supremo hacedor y componedor, que es poderoso de hacer comedias, tragedias y representaciones vivas; digo, hacer que pasen naturalmente y en lo ex-

general, fuentes y estudios, coords. Jesús M. ${ }^{a}$ NiETo IBÁÑEz, Raúl LóPEZ LÓPEZ, Antonio Reguera Feo y Manuel A. Seoane Rodríguez (León: Universidad de León, 2015) pág. 79.

${ }^{45}$ Discursos sobre el Eclesiastés, pág. 283.

${ }^{46}$ Discurso sobre materias del Consejo de Estado, fol. $27 \mathrm{v}$.

${ }^{47}$ Discursos sobre el Eclesiastés, pág. 85. 
terior cosas que sean símbolos y jeroglíficos de doctrinas interiores del espíritu, cuales son no sólo ésta sino otras muchas, o todas las historias de la Sagrada Escritura ${ }^{48}$.

La mirada retrospectiva en busca del origen de la pesadumbre de la vida conduce en los dos textos hasta el Paraíso; la caída de los primeros padres y el pecado original marcaron para siempre a sus descendientes. «Esta ocupación y negociación trabajosa dio el Gobernador a hijos de Adán para afligirse en ella», traduce el intérprete el versículo 13 del libro primero del Eclesiastés ${ }^{49}$. Y es que todos somos trasunto de aquel primer hombre:

Este Adán y este hombre que siempre aquí va poniendo no lo hemos de ir a buscar fuera de nosotros, que éste es el común y más fuerte engaño, sino en nosotros mismos hemos de mirar atentamente el sujeto, y el hombre y el Adán de toda esta obra y de todo este argumento, y mirar nuestros designios e inclinaciones con cuidado, y veremos clara y distintamente en nuestros mismos senos y entrañas el vivo comentario y la glosa de todo esto $^{50}$.

Por esta razón, el influyente político que buscaba en el Discurso de Pedro de Valencia una guía de conducta privada y pública, se encuentra con una exposición sobre los primeros capítulos del Génesis y las nefastas consecuencias del terrible error de los primeros padres:

En las palabras que dice Dios después de esto al hombre y a su mujer les declara y denuncia las calamidades y penas en que por su obra, quebrantando el precepto, habían incurrido, y con las miserias y trabajos del ánimo y del cuerpo que habían de sustentar y pasar la vida temporal hasta la muerte del cuerpo que les impone como pena de la parte animal, y como favor y bien del hombre interior ${ }^{51}$.

De aquella mortal desobediencia se derivan el pecado, el sufrimiento y la muerte física. El relato de cómo y por qué sucedió esta tragedia ocupa numerosas consideraciones en el intérprete y en buena parte de la exposición de Pedro de Valencia. En el principio, Dios dividió en dos partes el

\footnotetext{
${ }^{48}$ Discurso sobre materias del Consejo de Estado, fol. 41r-v.

${ }^{49}$ Discursos sobre el Eclesiastés, pág. 105.

${ }^{50}$ Discursos sobre el Eclesiastés, pág. 207.

${ }^{51}$ Discurso sobre materias del Consejo de Estado, fols. 61v-62r.
} 
alma humana: la superior, racional y masculina, y la inferior, sensitiva y femenina; a cada una le encargó una misión; como cumplían con rectitud su cometido, y la razón era la «señora» de la casa, la armonía reinaba entre ellas y su Creador. Se dice en el comentario del Eclesiastés:

Dios crió al hombre muy lleno de sabiduría y de muy claro y alumbrado entendimiento, $y$, de tal suerte, que no tenía necesidad de mendigar con los sentidos lo que para su perfección y menester le era necesario; antes desde allí los sentidos eran alumbrados y se gobernaba todo a las derechas, siendo la razón la primera. Y, como es la señora y el varón, por mejor decillo, que mandaba en casa, y todos los demás instrumentos y potencias no eran sino ministros, que, con gran suavidad y gusto, ejecutaban lo que por aquellas también ordenadas leyes les era intimado, de suerte que no deprendía el hombre primero con los ojos y con los oídos y después se presentaba aquello allá dentro como de nuevo para que se escogiese o se repudiase después de bien conocido y se le pusiere nombre, sino que allá dentro estaba la regla y la maestría, y de allí descendía por sus grados a las potencias exteriores que lo ponían en ejecución ${ }^{52}$.

También en el Discurso de Valencia se encuentra la doble potencia genérica de las partes del alma:

Hizo, pues, Dios a los hombres varón y hembra; no solamente que en lo exterior y visible fueron dos, Adán, varón, y Eva, mujer, sino que en lo interior cada uno de ellos de por sí tenían dos partes, una el hombre interior que es varonil y le pertenece el dominio y gobierno, y se llama espíritu y porción superior; y otra la parte exterior, inferior y femenina en que están los sentidos y apetitos corporales que debe ser obediente y conformarse con la parte superior, y se llama en la Escritura anima ${ }^{53}$.

La expresión «Dios crió al hombre derecho», referida a esta armonía interior en el alma primigenia, se repite en las dos obras. Así aparece en los Discursos:

Dios crió al hombre derecho, porque su natural, liso y derecho es; que, pues es una criatura que consta de dos partes, inferior y superior, sensitiva y racional, que era cosa derecha y puesta en razón que la superior mandase y la inferior obedeciese, que aquélla enseñase y ésta oyese y obedeciese, aquélla fuese la guía y ésta fuese la que siguiese a quien le guiase,

\footnotetext{
${ }^{52}$ Discursos sobre el Eclesiastés, pág. 106.

${ }^{53}$ Discurso sobre materias del Consejo de Estado, fol. $32 \mathrm{v}$.
} 
aquélla la señora y ésta la sierva; y finalmente y mejor que aquella que se llama hombre interior fuese el varón y marido, y esta que es exterior fuese la hembra y la mujer ${ }^{54}$.

Cuando se refiere a esta idea, Pedro de Valencia recuerda precisamente al Sabio, epíteto con el que se conoce a Salomón, a quien se atribuye la composición del Eclesiastés:

Y por estar en unidad y conformidad entre sí con Dios el varón y hembra, digo, la porción superior y la inferior, también a ella pasaba la luz del Verbo; y del hombre interior y sus sentidos e ingenio terreno e inferior, sus ojos, que también la parte animal tiene para las cosas corpóreas y de su jurisdicción, estaban alumbrados con el mismo resplandor y enhilados en correspondencia con los ojos del espíritu, y no veían ni miraban nada de por sí, sino que por ellos veía el espíritu derechamente y sin rodeos ni discursos y dudas también las cosas corpóreas y sus naturalezas y esencias. Y esto es lo que dice el Sabio, que crió Dios al hombre derecho y sano, y que él después se revolvió y mezcló con muchas cuestiones y dudas ${ }^{55}$.

El equilibrio del hombre interior se complementaba con la igualdad natural entre los dos sexos, creados por Dios a su imagen y semejanza:

No tenían cosa fea, ni hallaban en sí ejercicio ni uso torpe, ni tenían inclinación a él porque se debiesen tener por vergonzosos, ni se procurasen encubrir, así que el no avergonzarse desnudos no procedía de rusticidad ni de ignorancia, sino de sabiduría y aprobación de su naturaleza, que era buena y de seguridad de sus conciencias ${ }^{56}$.

Pero esta armonía se va a romper tras el engaño del demonio que les promete que serán como dioses; llega entonces la desobediencia y la expulsión del Paraíso. En este punto se encuentra una de las coincidencias más significativas entre los Discursos sobre el Eclesiastés y Pedro de Valencia. Al señalar al culpable último de la ruptura del hombre con Dios, los dos textos apuntan directamente a Eva; fue ella quien se dejó engañar por la astuta y malvada serpiente, arrastrando después a Adán a la perdición. A partir de aquí, el sexo femenino sale muy mal parado; seducción y frivolidad, es lo que único que cabe esperar de él. Las frases más duras

\footnotetext{
${ }^{54}$ Discursos sobre el Eclesiastés, pág. 224.

${ }^{55}$ Discurso sobre materias del Consejo de Estado, fol. 35r.

${ }^{56}$ Discurso sobre materias del Consejo de Estado, fol. 39r.
} 
en este sentido se encuentran en los Discursos. En diversos pasajes se pinta «a los hijos de Adán, muy muy hijos de Adán en esto, de aquel Adán ya vencido de sus apetitos y persuasiones flacas de su mujer» ${ }^{57}$. El intérprete se muestra especialmente irritado ante los devaneos femeninos que envuelven al hombre:

¿Quién sabe hacer estas tramas, dice el sabio, y quién puede juntar lo que repugna y está más lejos de otro que el cielo de la tierra? ¿Y quién sabe juntar lo dulce con lo amargo, lo cuerdo con lo loco? Ésta es la mujer, que sí te enreda y te enlaza y prende debajo de sus marañas y embustes. Porque no es otra cosa su corazón sino un nido de estos basiliscos y monstruos, y aquella dulzura de fuera es más que la hiel amarga (y tal estaba en este punto la memoria de Salomón de lo que con ellas le había pasado), que por eso dice que lo halló y lo vio ser así, y permitiolo Dios para el desengaño de todos ${ }^{58}$.

El juicio contra las mujeres no puede ser más negativo cuando trata sobre el pecado de soberbia que los llevó a caer en el engaño de la serpiente:

Eritis sicut dii scientes bonum et malum, que también aquí va descubriendo su intento y a este propósito secreto toca lo que se sigue de los hombres. Muy pocos dan en ello: de mil, uno; de las mujeres, ninguna. Y es necesario ser así, porque son las raíces del mal, y de una fuente no sale agua dulce y amarga ${ }^{59}$.

La tensión se relaja un poco cuando el autor especifica que al hablar de «la mujer» se refiere no tanto al sexo femenino como a una de las dos partes que, según hemos visto, componen el alma de todo hombre. Así, se dice:

Y no piense que lo que sólo pasaba a la letra en Adán y Eva por de fuera, no pasase en cada uno de ellos enteramente, que ya has visto cómo en Adán hay hombre y mujer, y lo mismo entiende que hay en Eva, que así lo significó la Sagrada Escritura diciendo: Masculum et foeminum creavit eos ${ }^{60}$.

Bien es verdad que fue el propio «Gobernador» quien colocó en la parte femenina del alma la merced de disfrutar los placeres del mundo:

\footnotetext{
${ }^{57}$ Discursos sobre el Eclesiastés, pág. 108.

${ }^{58}$ Discursos sobre el Eclesiastés, pág. 220.

${ }^{59}$ Discursos sobre el Eclesiastés, pág. 223.

${ }^{60}$ Discursos sobre el Eclesiastés, pág. 224.
} 
Esta pequeña y afeminada parte, que tal es la que aquí acaba de decir en respecto de las cosas fuertes que da Dios de su mano a los suyos y a los que de veras son hombres, son de poquísima estima, porque los regalos y contentos de esta vida para mujeres son, que no para varones que nacieron para ejercicios de obras grandes ${ }^{61}$.

En la obra de Valencia se manifiesta la misma oscilación entre el juicio de valor que le merece la mujer, por una parte, y la negatividad de la «parte mujeril» del alma, por otra. Aquí hay una diferencia de grado en relación con los Discursos; Valencia, que dedica buena parte de su tratado a tratar de explicar cómo pudo Eva caer en las redes de la serpiente, se esfuerza por salvaguardar la dignidad de la mujer como criatura de Dios, insistiendo en mayor medida que el intérprete en que las afecciones sensitivas, la inconstancia, la seducción y la soberbia son vicios ubicados en la parte femenina del alma en ambos sexos. «Siempre que decimos «la mujer» entendemos en ella la parte femenina y sensitiva del hombre» ${ }^{62}$, aclara el humanista. El demonio preparó su engaño entrando por esta parte:

El enemigo de la gloria de Dios y del bien de los hombres los acometió por la mujer, y en la misma mujer por la mujer, por la porción exterior, animal y femenina. Y bastó ocasión y modo como cogerla a solas, apartada y divertida del varón, y de su consejo, socorro y ayuda ${ }^{63}$.

Según Valencia, la mayor astucia de la serpiente consistió en manipular las palabras que Dios había dirigido a Adán y Eva prohibiéndoles comer el fruto del árbol de la ciencia del bien y del mal. A fin de que la mujer no percibiese la trampa que le estaba tendiendo, cambia el número y el género de los verbos:

Y habiendo hablado por verbos singulares masculinos (que en aquella lengua denotan los verbos no sólo diferentes números y personas, sino también sexos): comederis tu mas, morte morieris mas, ella lo refirió por verbos plurales y femeninos: moriamur femenine ${ }^{64}$.

También los sustantivos los pronuncia ambigüamente. El caso más palmario es el uso de «ojos»:

\footnotetext{
${ }^{61}$ Discursos sobre el Eclesiastés, pág. 157.

${ }^{62}$ Discurso sobre materias del Consejo de Estado, fol. 48v.

${ }^{63}$ Discurso sobre materias del Consejo de Estado, fol. 44r.

${ }^{64}$ Discurso sobre materias del Consejo de Estado, fol. 46v.
} 
Considerados los ojos humanos según las dos maneras de vistas o facultades visivas que hemos dicho, según la primera y superior se llaman 'ojos altos y superiores' en la lengua original, siendo un mismo nombre del número dual PHENAIM; cuando se dice de los ojos superiores y su vista es masculino, y cuando se entiende de los inferiores y de la vista terrena es femenino, que por esto he dicho algunas veces en este discurso "las ojos" ${ }^{65}$.

Valencia se detiene a explicar in extenso cómo la serpiente utilizó a su manera esta dualidad de género; a juicio del humanista, la confusión entre los ojos del espíritu y los corporales es clave para llegar a comprender cómo pudo triunfar en la mujer la palabra del demonio frente a la de Dios mismo:

La cual anotación se confirma con lugares de la Sagrada Escritura, y contiene misterio, advertido por el mismo Espíritu Santo en la narración de esta historia, porque en las palabras de la serpiente muestra que las pronunció con engaño, no declarando con el género del nombre ni del verbo cuáles ojos decía, los masculinos o los femeninos, porque dijo VENIPHKEHV GHENEICHEM, “y abriranse ojos de vosotros”; pero el Espíritu Santo, cuando dijo el efecto que había hecho la transgresión declaró que los ojos fueron VETIPAKAHHNAGEI SENEIHEM, "y fueron abiertas las dos ojos de ambos a dos", así que los ojos de la hembra y del varón se abrieron, también los del entendimiento como los del sentido, pero en la vista femenina e inferior por la parte y hacia donde estaban cerrados $^{66}$.

Por lo tanto, el ser humano no puede olvidar que en su interior lleva al varón y a la hembra, y que ésta continúa intentando seducirlo y conducirlo al error, como ocurrió en el principio. Dice el intérprete:

Y considera atentamente las artes y las redes que ésta tu parte mujeril y flaca te arma, y sabe con prudencia sacar el pie de ellas. Porque has de saber que ahora por tu culpa tú no estás derecho, como cuando te crió Dios; que ahora la parte superior y tu razón y entendimiento van a mendigar de los sentidos, y pasan primero y se registran en la aduana del apetito todas las cosas, y ella las marca allí de su yerro y señal ${ }^{67}$.

\footnotetext{
${ }^{65}$ Discurso sobre materias del Consejo de Estado, fols. 52v-53r.

${ }^{66}$ Discurso sobre materias del Consejo de Estado, fol. 53r.

${ }^{67}$ Discursos sobre el Eclesiastés, pág. 225.
} 
También insiste en esto el Discurso de Pedro de Valencia:

Y esto hace el hombre llevado de la concupiscencia del pecado, y de la ley, imperio y brío de la carne que quedó viva, imperiosa y traviesa y desobediente al hombre interior, aunque le fue mandado por Dios, debajo de la persona de la mujer, que estuviese sujeta al varón y siguiese sus preceptos. Pero su espíritu y aliento de ella, y a lo que siempre aspira es a la muerte y a las obras de ella, que son los pecados ${ }^{68}$.

Sea como fuese, a pesar del engaño, de la desobediencia y la caída, la eternidad que Dios infunde en el hombre a través del alma racional y la ley natural que lo conectan con Él no se pierden en ningún momento. Así lo deja ver la lengua hebrea, según la interpretación del Eclesiastés:

En la lengua santa hay dos voces para significar el alma. La una se dice nepeř, y la otra $r \hat{u}^{a} h$. La primera significa aquella parte del alma con que mira las potencias inferiores y tiene como a su cargo proveer la parte animal y sensitiva y socorrer con sus espíritus animales las partes que se ejercitan en esto sensitivo. Y la otra es la parte que mira las cosas más levantadas y excelentes del hombre, que son la razón, el libre albedrío y las cosas que tienen eternidad y duración perpetua como ella es. Otra voz hay entre estas dos que se llama nəšâmā, y a esta voz se le añade el hayyîm, que quiere decir vidas, y siempre se le atribuye al hombre que tiene dos vidas, lo que no tiene otro animal, porque no son inmortales como el hombre ${ }^{69}$.

La misma luz de la razón, insuflada por Dios en la creación del hombre, así como las «dos vidas» de éste aparecen en la obra de Valencia:

Este ángel, esta naturaleza que es del linaje de la luz espiritual y divina, está en una carne con el animal, y hace un hypostasis o supuesto humano, porque con un soplo o huelgo de vida o de dos vidas (como se lee en hebreo), que es el ánima racional que inspira Dios por nueva creación en la imagen terrena que había formado, se informó aquella materia, y se hizo el hombre in animam viventem ${ }^{70}$.

De todo ello se colige, a modo de conclusión final, que el temor de Dios debe ser la premisa sobre la que se asiente la vida humana en todas sus dimensiones. Así lo señala el intérprete:

\footnotetext{
${ }^{68}$ Discurso sobre materias del Consejo de Estado, fol. 63r.

${ }^{69}$ Discursos sobre el Eclesiastés, págs. 143-144.

${ }^{70}$ Discurso sobre materias del Consejo de Estado, fols. 37v-38r.
} 
Digna conclusión y digno fin y remate del sapientísimo Salomón. Dos cosas debe el hombre a Dios, la obediencia a sus preceptos y el temor y reverencia a su majestad divina. Y esto es todo el hombre ${ }^{71}$.

Y lo mismo, Pedro de Valencia:

Si no nos persuadimos y creemos con firmeza que lo más conveniente para nuestras cosas, para nuestro estado y aumento es lo justo y lo bueno y conforme a la divina voluntad y ley, no solamente aborrecemos a los padres, madres y maestros, y a todos los superiores y prelados, y a todos los hombres que nos inducen e impelen a vivir virtuosamente, y no estorban el seguir nuestros antojos sino al mismo Dios querremos mal dentro de nosotros, porque es el supremo y más fuerte príncipe que nos impide los apetitos e intentos injustos ${ }^{72}$.

Es interesante ver cómo Valencia asienta esta afirmación con el testimonio de Plutarco:

Y así dice muy bien Plutarco que el seguir a la razón es seguir a Dios, y que solos los que siguen a la razón debemos tener por libres, porque solos han deprendido lo que se ha de querer, y viven como quieren, y que los que siguen los ímpetus de los apetitos irracionales viven infamemente y no como libres y generosos, pues sirven a la parte irracional haciendo lo que no querrían, a lo menos lo que no quiere el hombre interior ${ }^{73}$.

El recurso a los autores de la Antigüedad clásica como exempla -«la similitud es para los animales, el ejemplo para los hombres» ${ }^{74}$, dice el intérprete-, es una nota común en los dos textos, y se puede inscribir en el uso que ambos hacen del método humanístico (fuentes originales y crítica textual, etimologías léxicas, explicaciones retóricas, etc.). En la interpretación del Eclesiastés se menciona al «valiente y fuerte» Aquiles y al «astuto y sagaz» Ulises para recordar que nada queda ya de ellos ${ }^{75}$; la caverna de Platón nos habla de que «todo es sombra y no tiene más de la apariencia» ${ }^{76}$; Julio César y Alejandro Magno son «de los que llamamos

\footnotetext{
${ }^{71}$ Discursos sobre el Eclesiastés, pág. 284.

${ }^{72}$ Discurso sobre materias del Consejo de Estado, fol. $68 \mathrm{v}$.

${ }^{73}$ Discurso sobre materias del Consejo de Estado, fol. 63r.

${ }^{74}$ Discursos sobre el Eclesiastés, pág. 281.

${ }^{75}$ Discursos sobre el Eclesiastés, pág. 138.

${ }^{76}$ Discursos sobre el Eclesiastés, pág. 207.
} 
hombres de veras y de chapa, y magnánimos ${ }^{77}$; Juvenal confirma la triste situación del hombre casado sometido a los dictados de su esposa ${ }^{78}$, etc. Pedro de Valencia también aprovecha las sentencias morales de Eurípides $^{79}$; autoriza con Píndaro la etimología de aristotechnas, «que quiere decir sumo y perfectísimo artífice» ${ }^{80}$; apoya con Heráclito la necesidad de obedecer a Dios y evitar así la venganza de las Furias, «defensoras de la divina justicia» ${ }^{81}$; con Sócrates, «que parece se le debe de creer lo que él dice en su Apología, que lo había dado Dios a los griegos para despertarlos de la modorra en que estaban», certifica que el peor engaño del demonio a los hombres fue anteponer lo útil a lo justo, algo completamente pernicioso para el hombre y la república ${ }^{82}$; Sócrates y Séneca invocan la sabiduría que imprime el sufrimiento, porque «cualquiera es bastantemente elocuente para hablar en lo que sabe, cuánto más en lo que padece» ${ }^{83}$, etc.

Además de los señalados aquí a propósito del Discurso sobre materias del Consejo de Estado, los paralelismos literarios entre los Discursos sobre el Eclesiastés y las obras de Pedro de Valencia se extienden a muchas de ellas, de forma particular a las dedicadas a la exégesis bíblica. Es el caso del trabajo que el humanista dedica al comentario de los Hechos de los Apóstoles y de la Epístola a los Gálatas de San Pablo ${ }^{84}$, que trae a la mente el cierre que el intérprete del Eclesiastés le pone a su obra, criticando la errónea interpretación que tales textos neotestamentarios están recibiendo en su momento (precisamente en plena expansión de la teología reformista):

\footnotetext{
${ }^{77}$ Discursos sobre el Eclesiastés, pág. 173.

${ }^{78}$ Discursos sobre el Eclesiastés, págs. 220-221.

${ }^{79}$ Discurso sobre materias del Consejo de Estado, fol. 28r.

${ }^{80}$ Discurso sobre materias del Consejo de Estado, fol. $35 \mathrm{v}$.

${ }^{81}$ Discurso sobre materias del Consejo de Estado, fol. 39v.

${ }^{82}$ Discurso sobre materias del Consejo de Estado, fol. 66v.

${ }^{83}$ Discurso sobre materias del Consejo de Estado, fol. $57 \mathrm{v}$.

${ }^{84}$ Pedro de VALENCIA, «Para declaración de una gran parte de la estoria apostólica en los Actos y en la Epistola ad Galatas advertencias», ed. y trad. M. a del Prado Ortiz SÁnchez, en Pedro de Valencia. Obras completas. Volumen II, coord. Jesús M. ${ }^{a}$ NiETo IBÁÑẼ (León: Universidad de León, 2014) págs. 293-537.
} 
Esta es la gracia del Evangelio tan rara en nuestros tiempos y tan copiosa en aquellos primeros, de que tan llenos están los Actos y Epístolas de los Apóstoles, tan mal entendida de muchos teólogos de nuestros tiempos, que no penetran la dignidad del Evangelio. Y ansí nos pedirá Dios cuenta de lo que a nuestra parte toca de cumplir ${ }^{85}$.

El profundo apego a la teología paulina caracteriza esta y todas las obras bíblicas del humanista. También el intérprete muestra particular querencia por San Pablo. De hecho, dedica uno de los capítulos finales a la explanación de la dicotomía «ley y gracia» siguiendo las directrices de la Epístola a los Hebreos, atribuida al Apóstol; esta cuestión es desarrollada ampliamente en la obra de Valencia. Asimismo, la encendida alabanza del Padrenuestro que hace el autor de los Discursos, en una manifiesta defensa del interiorismo en la relación con Dios por encima de enrevesadas y oscuras fórmulas litúrgicas, recuerda el magnífico tratado en el que Pedro de Valencia explica los símbolos que configuran esta oración universal $^{86}$ :

No hay para qué fatigarse en multiplicar palabras, sino presentar pura y sencillamente el corazón delante de su grandeza y tomar la lección que en esto Él mismo nos dio, cuando nos enseñó a orar con aquella breve y altísima oración que nos compuso y quiso que la dijésemos cuando orábamos, en que nos encerró todos los secretos del nuevo y viejo Testamento, y cuanto de Dios podemos y debemos pretender y desear ${ }^{87}$.

Una de las mayores contribuciones de Pedro de Valencia para la renovación religiosa de su tiempo fue el impulso que dio a la difusión de la espiritualidad de San Macario el Egipcio, representante de la Iglesia primitiva y del genuino ascetismo religioso, con la traducción del original griego (al latín y, en algún caso, al castellano) de sus Homilías espirituales y de algunos Opuscula ${ }^{88}$. Los temas centrales de muchas de estas obras

\footnotetext{
${ }^{85}$ Discursos sobre el Eclesiastés, pág. 285.

${ }^{86}$ PedRo DE VAlencia, «Ad orationem dominicam illam 'Pater noster, qui es in coelis' symbola», ed. y trad. Abdón Moreno García, en Pedro de Valencia. Obras completas. Volumen II, coord. Jesús M. ${ }^{a}$ NiETo IBÁÑ̃EZ (León: Universidad de León, 2014) págs. 225 293.

${ }^{87}$ Discursos sobre el Eclesiastés, pág. 186.

${ }^{88}$ La traducción castellana de Pedro de Valencia de las Homilías espirituales V y IX de San Macario se encuentra también en la Biblioteca de El Escorial, Ms. CIII.15, fols. 259-267.
} 
coinciden con los Discursos sobre el Eclesiastés: la lucha entre el bien y el mal que sacude al hombre comienza con Adán y su desobediencia en el Paraíso, a su culpa se debe la entrada en el mundo del pecado y de la muerte, los bienes mundanos son vanos y despreciables, el hombre interior ha de poner todo el entendimiento en alcanzar la sabiduría y el espíritu de Dios, la búsqueda de la verdad representa un camino lleno de trabajos y tentaciones, etc. ${ }^{89}$ La disertación sobre las dos partes del alma humana, y la necesidad del gobierno y señorío de la superior y varonil sobre la inferior y femenina, la desarrolla Valencia ampliamente también en un Discurso que dirige a la reina Margarita de Austria, esposa de Felipe III ${ }^{90}$. Las referencias al campo y al trabajo de la tierra, metáforas de la siembra y la siega, recorren el comentario del Eclesiastés. Tales referencias nos llevan a tantos y tantos escritos sociales del humanista, sus memoriales y discursos dirigidos al Rey sobre el precio y la tasa del pan, la limosna o las enfermedades y la salud del reino, entre otros temas abordados en este terreno. En uno de ellos, el Discurso sobre el acrecentamiento de la labor de la tierra, dirigido al rey Felipe III, señala precisamente el temor de Dios y el cultivo racional de la tierra, con su consiguiente aumento demográfico, como los bienes principales que el monarca ha de cuidar para enriquecer la hacienda real al servicio de sus ciudadanos. Así se alcanza la felicidad en la República, tal como ocurrió en el reino de Salomón, según se dice en la Sagrada Escritura ${ }^{91}$. La extensa epístola que dirige en torno a 1590 a Alonso Ramírez de Prado, fiscal de Hacienda de Felipe II, es un alegato contra la sabiduría de la carne que invade al hombre interior del viejo Adán por obra del demonio; el temor de Dios y el servicio al bien público han de ser las señas de identidad de un ministro real, apartado de la vanidad y la pompa que sólo causan tormento a quien las coloca como

\footnotetext{
${ }^{89}$ Vid. Pedro de Valencia. Obras completas. Volumen IX (Valladolid: Consejería de Educación y Cultura - León: Universidad de León, 2001).

${ }^{90}$ Pedro de VAlencia, «Borrador de un discurso a la reina Doña Margarita, fundadora de un monasterio de religiosas de San Agustín», en Pedro de Valencia. Obras completas. Volumen IV: Escritos sociales. 2, Escritos políticos, eds. Rafael GonzÁlez CaÑal e Hipólito Benjamín Riesco Peláez (León: Universidad de León, 2000) esp. pág. 489.

${ }^{91}$ Pedro de VALENCIA, «Discurso sobre el acrecentamiento de la labor de la tierra. Madrid, 1607», en Pedro de Valencia. Obras completas. Volumen IV/1: Escritos sociales. 1. Escritos económicos, ed. Rafael GonZález CaÑal (León: Universidad de León, 1994) págs. 137-158.
} 
fin de su vida ${ }^{92}$. El autor de los Discursos destaca el inmenso esfuerzo que el sabio ha de hacer en la búsqueda de la verdad. En uno de estos pasajes dice así:

El que ha caminado y sudado y fatigádose, consumido mucho aceite y mucho tiempo y echa de ver la selva y la espesura de las opiniones y sectas nacidas de los propios antojos y fantasías de los hombres y que ha querido hallar fundamento y suelo en lo que no le tenía y recoger y hacer alarde y poner en orden tantos fieros monstruos de tantas y tan diversas cabezas, ¿qué ha de decir después de largas pruebas, sino que cuanto más ha allegado de esto, tanto más dolor ha acumulado? ?3 $^{3}$

Bien podría conocer de primera mano el trabajo de esta indagación alguien que como Pedro de Valencia lo había padecido para la elaboración de sus Academica sive de iudicio erga verum, publicados en las prensas de Plantino en $1596^{94}$; en ellos repasa concienzudamente el criterio de verdad propuesto por las escuelas de la Antigüedad para la adquisición del conocimiento, diferenciando criterios racionales de las meras opiniones y fantasías. A propósito de los «fieros monstruos», llama la atención por su vehemencia el párrafo de los Discursos que ensalza a los sabios de la Biblia,

a cuyas manos vinieron primero desde la boca de Dios las ciencias y disciplinas sin irlas a mendigar a los sedientos arroyuelos de los filósofos gentiles, que aún no habían salido al mundo tan asquerosos monstruos ${ }^{95}$.

En el arranque de un breve opúsculo filosófico, Valencia lanza esta misma acusación contra los sabios paganos que, careciendo de la luz de Dios, «han engendrado innumerables monstruos de falsos juicios» ${ }^{96}$, como le ocurre a Platón, por ejemplo, cuando

\footnotetext{
${ }^{92}$ Pedro de Valencia a Alonso Ramírez de Prado, en Pedro de Valencia, Epistolario, eds. Fco. Javier Fuente Fernández y Juan Fco. Domínguez Domínguez (Madrid: Ediciones Clásicas, 2012) págs. 59-79.

${ }^{93}$ Discursos sobre el Eclesiastés, pág. 117.

${ }^{94}$ Pedro de Valencia, Academica, en Pedro de Valencia. Obras completas. III, Académica, ed. Juan Fco. Domínguez Domínguez, con la col. de Jesús M. ${ }^{a}$ Nieto IbÁÑez (León: Universidad de León, 2006).

${ }^{95}$ Discursos sobre el Eclesiastés, pág. 103.

${ }^{96}$ Pedro de Valencia, Humanae rationis Paralogismáton illustriora exempla, ed. Avelina CARRERA DE LA RED, en Pedro de Valencia: Obras completas. VI, Escritos varios, coord. Jesús M. ${ }^{a}$ Nieto IbáÑEz (León: Universidad de León, 2012) pág. 97.
} 
ensucia su insigne tratado Sobre la inmortalidad del alma trayéndose de los estercoleros egipcios la obscena mentira de la palingenesia, al tiempo que conscientemente toma de los hebreos dogmas limpios como la patena ${ }^{97}$.

\section{CONCLUSIÓN}

El autor de los Discursos sobre el Eclesiastés y Pedro de Valencia colocan el temor de Dios y la prístina vida del Evangelio en el centro de la vida humana; hacia allí es hacia donde el hombre debe dirigir su entendimiento. En ello están, sin duda, igualmente Benito Arias Montano y muchos otros humanistas. En cualquier ámbito del conocimiento, la Biblia ha de ser la fuente fundamental. Para llegar a penetrar a fondo su significación, es imprescindible retornar a las fuentes de las Escrituras, explicar sus lenguas originarias y profundizar en el contexto en el que nacen. Sin embargo, no se trata de una labor meramente hermenéutica; en tiempos de enorme confusión en la Iglesia, se necesita recuperar la auténtica educación nacida del humanismo cristiano, a fin de contribuir a la renovación de la sociedad frente a la corrupción e indolencia moral que la atenazan. Para ello es bueno dirigirse en primer lugar a aquellos que detentan el poder en cualquiera de sus escalas e instituciones.

Dentro de esta comunidad de misión, las concordancias textuales y de pensamiento entre el intérprete del Eclesiastés y Pedro de Valencia los acercan de una forma particular. Como se ha podido comprobar, uno y otro coinciden estrechamente en su particular afición por remontarse al adanismo; en el principio la armonía en el hombre interior era absoluta; las dos partes de su alma (la superior, masculina y racional, y la inferior, femenina y sensitiva) estaban en estrecha conexión entre sí y, lo más importante, con la razón divina; tras su expulsión del Paraíso, provocada en buena medida por la debilidad de la mujer, o mejor dicho, de la parte femenina del alma, el hombre debe esforzarse en ejercer el control de su vida entera, tratando de no perder nunca la unión con su Creador. El aviso dominante que emana de la lectura de estos textos es la necesidad

\footnotetext{
${ }^{97}$ PedRo de VAlencia, Humanae rationis Paralogismáton illustriora exempla, ed. Avelina CARRERA DE LA Red, en Pedro de Valencia: Obras completas. VI, Escritos varios, coord. Jesús M. ${ }^{a}$ Nieto IbáÑEz (León: Universidad de León, 2012) pág. 99.
} 
de conocer y aplicar en la vida personal y pública la ley natural infundida por Dios en su corazón para mantener vivo el lazo que los une a Él desde aquel día primero. Esto es lo único que vale la pena; todo lo demás no es sino vanitas vanitatis.

Esta proximidad de pensamiento, las numerosas coincidencias textuales que se dan entre los Discursos y algunas obras de Valencia, la entusiasta predilección que éste siente por los discursos en castellano, así como las referencias en tercera persona a Benito Arias Montano en los tres manuscritos que transmiten el texto, son, a mi juicio, claros indicios si no de la autoría del humanista (tema que no se puede resolver hasta el momento taxativamente por la falta de referencias externas más concretas), al menos sí de su activa participación en la interpretación literal del Eclesiastés.

Recibido: 12/04/2018

Aceptado: 01/06/2018 